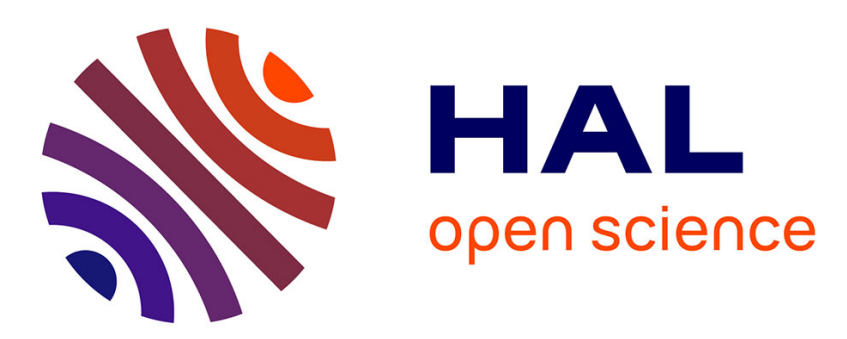

\title{
Numerical investigation of soot-flame-vortex interaction
}

B. Franzelli, A. Cuoci, A. Stagni, M. Ihme, T. Faravelli, S. Candel

\section{To cite this version:}

B. Franzelli, A. Cuoci, A. Stagni, M. Ihme, T. Faravelli, et al.. Numerical investigation of sootflame-vortex interaction. Proceedings of the Combustion Institute, 2017, 36 (1), pp.753 - 761. 10.1016/j.proci.2016.07.128 . hal-01480272

\section{HAL Id: hal-01480272 \\ https://hal.science/hal-01480272}

Submitted on 13 Mar 2017

HAL is a multi-disciplinary open access archive for the deposit and dissemination of scientific research documents, whether they are published or not. The documents may come from teaching and research institutions in France or abroad, or from public or private research centers.
L'archive ouverte pluridisciplinaire HAL, est destinée au dépôt et à la diffusion de documents scientifiques de niveau recherche, publiés ou non, émanant des établissements d'enseignement et de recherche français ou étrangers, des laboratoires publics ou privés. 


\title{
Numerical investigation of soot-flame-vortex interaction
}

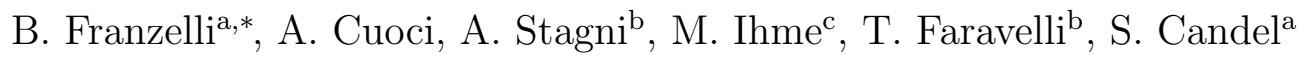 \\ ${ }^{a}$ EM2C, CNRS, CentraleSupélec, Université Paris-Saclay, 92295 Châtenay-Malabry \\ Cedex, France \\ bDepartement of Chemistry, Materials and Chemical Engineering 'G. Natta', Politecnico \\ di Milano, 20133 Milano, Italy \\ ${ }^{\mathrm{c}}$ Center for Turbulence Research, Stanford University, Stanford, CA 94305, USA
}

\begin{abstract}
Because the numerical simulation of soot production in turbulent flames is quite challenging, it is useful to consider simpler aerodynamic configurations retaining unsteady strain rate and curvature effects. The present article reports detailed numerical simulations of a planar vortex interacting with a sooting laminar diffusion flame formed by a parallel flow of acetylene and air. Calculations are carried out to reproduce the experimental data reported by Cetegen and Basu (Combust. Flame, 2006). Compared to previous numerical works on this configuration based on simple two-equations soot models, a detailed numerical mechanism, accounting for 97 gaseous species and 59 solid BINs, is considered here to represent the chemistry in the gas phase and the production and oxidation of soot particles. Three different vortex strengths are considered and vortices are formed by pulsing the air or the fuel streams, allowing comparisons between the calculated soot-vortex-flame
\end{abstract}

\footnotetext{
*Corresponding author

Email address: benedetta.franzelli@cnrs.fr (B. Franzelli)
} 
interactions with LII images. Calculations adequately retrieve experimental data when the vortex is initiated at the fuel side. Differences are observed when the vortex is formed on the air side. The simulations, however, are useful for examining strain rate and curvature effects on soot volume fractions of small spherical particles and large aggregates, and to study physical processes underlying the soot production. It is shown that the variability of the soot volume fraction is highly correlated to the response of soot precursors to flame curvature. Soot variability in the mixture fraction space depends on the behavior of large aggregates that, being characterized by high Schmidt numbers, are more sensitive to the convective motion imposed by the vortex compared to the gaseous phase. The observed behavior has to be reproduced by the models developed for numerical simulations in order to obtain an accurate prediction of soot production in turbulent flames.

Keywords: Soot; Curvature; Vortex; Strain rate; Heavy PAHs 


\section{Introduction}

Reducing soot emissions is of considerable importance for many practical applications due to their negative effects on the environment and on public health. In this context, substantial experimental and numerical efforts have been made to understand, characterize, and model the complex processes leading to soot formation and oxidation $[1,2,3,4]$.

Soot production ${ }^{1}$ in turbulent flames, which are most relevant in practice, is a complex process which depends on chemistry, flow history and local turbulence properties. The analysis of soot in fully turbulent flames is then extremely challenging. The experimental investigation requires the use of combined diagnostics to obtain quantitative measurements of soot distribution, its relation with respect to flow and flame quantities $[5,6,7,8]$. On the numerical level, Direct Numerical Simulations (DNS) of turbulent flames have been used to investigate the dependence of soot production on the flow history and local turbulence properties $[9,10,11,12,13,14,15,16]$.

Alternatively, simpler configurations may be used to study flame-flowsoot interactions for a reduced computational cost. This is exemplified in the cases of a laminar pulsed flame [17] or a diffusion flame wrapped-up by a line vortex [5]. In these two cases, measurements are more easily carried out than in fully turbulent flames because the phenomenon can be periodically reproduced. From a numerical standpoint, these configurations are attractive because they can be simulated using detailed models so that complex pro-

\footnotetext{
${ }^{1}$ Soot production indicates the net process comprising both formation and consumption contributions.
} 
cesses underlying soot production can be accurately described. Obviously, these fundamental studies do not replace the need for fully-turbulent simulations, but provide crucial information on the instantaneous and local effect of a vortex eddy on soot production that could be used to clarify the turbulent flame behavior and to guide the modeling efforts.

The flame-vortex interaction is specifically useful and has been extensively explored to investigate the effects of unsteady strain rate and curvature induced by vortices on the flame front [18]. Among various generic configurations, the case of a planar diffusion flame wrapped-up by a line vortex is considered in the present investigation and simulated with a detailed model for gas dynamics and soot particle production that cannot be afforded in DNS of turbulent flames. Using an elegant experimental design, Cetegen and Basu [5] were able to obtain soot volume fraction distributions from LII imaging. Previous numerical studies of this configuration $[19,20]$ have used simplified gaseous mechanisms and soot models based on semi-empirical twoequation representations, with a limited degree of generality. In the present work, we propose a detailed numerical simulation of soot-flame-vortex interaction based on a detailed description of both gas and soot, together with a direct comparison between experiments and simulations on the effect of vortices on soot production.

Calculations are carried out to examine effects related to the injection side and to the vortex strength. The paper begins with a review of the detailed kinetic mechanism (Section 2). The numerical setup is briefly presented in Section 3. The interaction of a vortex with soot is analyzed in Section 4 . The analysis focuses on the influence of curvature on the flame quantities 
governing soot production and on the effect of the flow field induced by the vortex on the soot layer.

\section{Detailed kinetic mechanism}

The kinetic scheme combines a detailed gas-phase mechanism (DGM) and a detailed soot mechanism (DSM) for the description of the formation and oxidation of soot.

The DGM consists of $\sim 170$ species and $\sim 6000$ reactions, describing the high-temperature pyrolysis and oxidation for a wide range of hydrocarbon fuels [21]. The mechanism has been tested over a wide range of conditions $[22,23]$.

The DSM was developed using the discrete sectional method [24]. Only the most relevant details are provided in what follows. PAHs (Polycyclic aromatic hydrocarbons considered soot precursors) are organized in two classes: light PAHs, including species up to pyrene, and heavy PAHs, including species with more than 4 aromatic rings. Heavy PAHs and particles are discretized into 20 classes of pseudo-species (called BINs) with their masses doubled from one class to the next. PAHs of more than 20 carbon atoms constitute the first four BINs. The first soot particles (BIN5) are modeled as clusters containing 320 carbon atoms. Particles between BIN5 and BIN12 are assumed to be spherical in shape with a mass density of $1500 \mathrm{~kg} \mathrm{~m}^{-3}$ [25]. BIN13 to BIN20 are treated as monodisperse aggregates, with fractal dimension of 1.8 [26]. The DSM features a total number of 100 lumped pseudo-species organized in 20 BINs, each of which has two or three subclasses (different $\mathrm{H} / \mathrm{C}$ ratios), split into radical or molecular surfaces. Six 


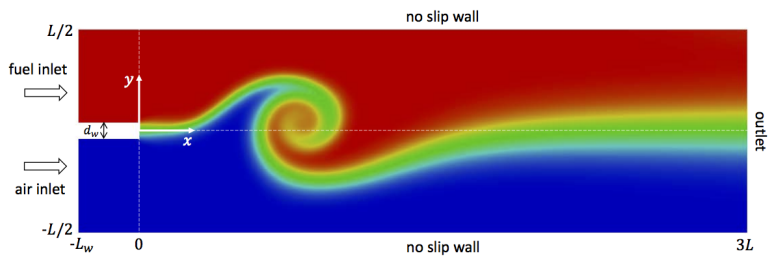

Figure 1: Schematic view of the computational domain: a planar diffusion acethylene/air flame is wrapped by a line vortex.

heterogeneous reaction classes are accounted for with appropriate kinetic parameters: hydrogen-abstraction-carbon-addition (HACA) mechanism; inception; oxidation; surface growth; dehydrogenation; coalescence and aggregation. The total number of reactions for the DSM scheme is $\sim 10500$.

To enable computational simulations, the mechanism was reduced with the Species-Targeted Sensitivity Analysis (STSA) technique [27]. The final mechanism, provided in the supplementary material, includes 156 species (97 gaseous species and $59 \mathrm{BINs}$ ) and $\sim 5600$ reactions. Species transport properties are calculated from the standard molecular theory of gases. Soot particles and aggregates are treated as gaseous species, so that their binary mass diffusion coefficients are calculated on the basis of a proper extrapolation from the binary mass diffusion coefficients of larger PAHs. Typical values of the Schmidt number for the soot particles range from 4 to 50 (at $1000 \mathrm{~K})$.

\section{Numerical setup}

The computational domain (Fig. 1) reproduces an experimental configuration [5], consisting of a $2 \mathrm{D}$ channel with length equal to $\left(3 L+L_{w}\right)$ and 
width equal to $L$, where $L=40 \mathrm{~mm}$ and $L_{w}=12 \mathrm{~mm}$. The two incoming streams, a mixture of acetylene and nitrogen (0.25/0.75 on a molar basis) on one side and air on the other side, are separated by a splitter plate of thickness $d_{w}=1.2 \mathrm{~mm}$. Both streams are injected at atmospheric pressure and temperature of $300 \mathrm{~K}$. The velocity of the incoming streams was fixed at $u_{c}=0.15 \mathrm{~m} \mathrm{~s}^{-1}$ with a flat profile at the channel inlet. Vortices are created by modifying the velocity-time profile at injection:

$$
\frac{u^{i n j}(\tau)}{u_{c}}=1+\beta V_{0} \exp \left[-\left(\ln \frac{\tau}{0.1}\right)^{2}\right] \text { with } \beta=4.5
$$

where $\tau=u_{c} t / L$ is the dimensionless time. The value of $V_{0}=1.5,2.0,2.5$ governs the circulation level and, consequently, the strength of the vortex induced by the velocity pulse. Details on the derivation and validation of the velocity boundary conditions are provided as supplementary materials.

Numerical simulations were carried out using the laminarSMOKE framework [28, 29], a CFD code specifically designed to solve multidimensional laminar reacting flows with detailed kinetic mechanisms. A passive scalar $Z(Z=0$ in the air stream and $Z=1$ in fuel stream) was also transported, assuming a diffusivity equal to that of $N_{2}$. This passive scalar $Z$ measures the degree of mixing between air and fuel streams. The thermophoretic and Soret effects are accounted for in the calculation. A uniform spatial discretization of $100 \mu \mathrm{m}$ is used on the first $3 / 4$ of the configuration where the soot-vortex-flame evolution is evaluated, resulting in more than 20 grid points to describe the flame reaction zone. The resolution is halved in the last part of the grid, necessary to evacuate the vortex. Second-order centered spatial discretization schemes were applied, while the time step, after a convergence study, was fixed to $2 \times 10^{-5} \mathrm{~s}$. Grid convergence was investigated by halving 

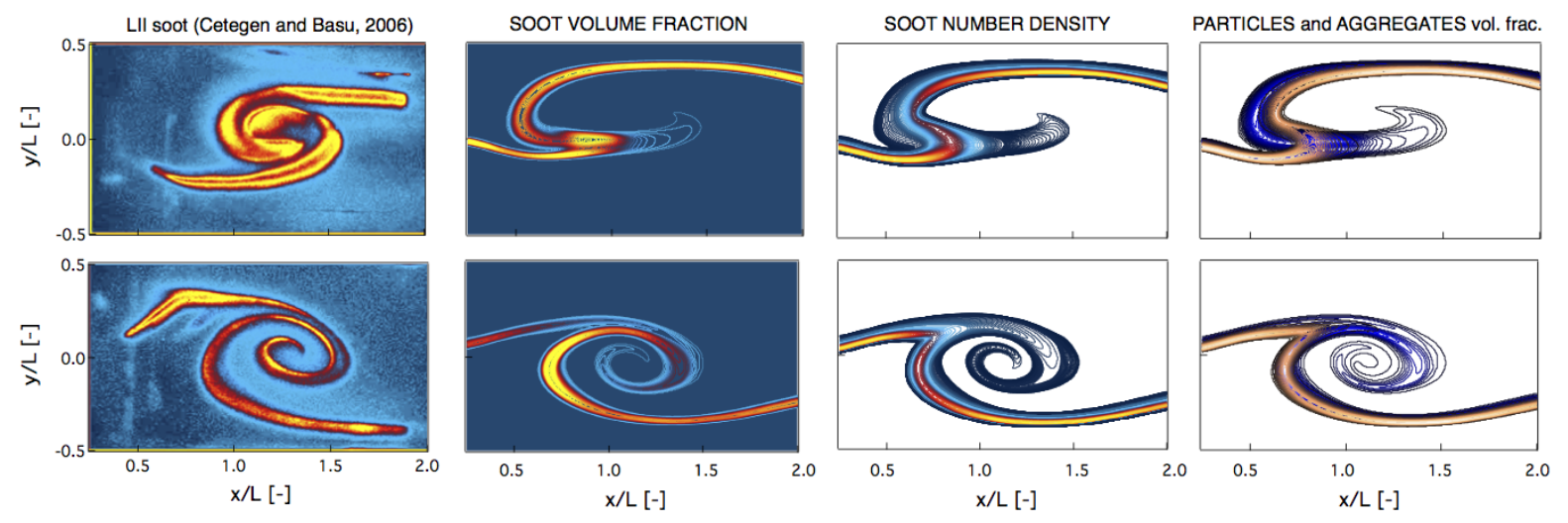

Figure 2: Soot topology for $V_{0}=2.0$ at $\tau=0.34$ for air-injection (top) and fuel-injection (bottom). First column: LII soot experimental results [5]. Second column: numerical soot volume fraction. Third column: numerical soot number density. Last column: Iso-contours of spherical soot particles (copper colormap) and of soot aggregates (blue colormap).

the number of cells, and noting that differences in soot volume fraction and particle number density remained below $5 \%$.

\section{Flame-soot-vortex interaction}

Experimental and numerical results representative for the vortex interaction with the soot field are shown in Fig. 2 for both air (top) and fuel (bottom) vortex injections. They correspond to the case $V_{0}=2.0$ at time $\tau=0.34$. For these conditions, the numerical soot volume fraction $f_{v}$ field (second column) can be compared with experimental LII data [5] (first column). ${ }^{2}$ It can be observed that soot particles form a layer that is rolled-up by the vortical field. A more pronounced roll-up of the soot layer is observed

\footnotetext{
${ }^{2}$ Following the notation given in [5], the experimental results correspond to a reduced time $\tau_{D}=t-\tau_{R}=62 \mathrm{~ms}$, where $\tau_{R} \approx 28 \mathrm{~ms}$ is the piston rise time.
} 
when the vortex is injected on the fuel side, which shows a fairly good agreement with the experimental results. In contrast, in the case of air vortex injection, the soot layer is less well wrapped by the vortex and there are noticeable differences between calculations and experimental data. Possible reasons for this difference will be discussed in Section 4.2, but it is important to highlight the fact that this is the first time that a comparison between experiments and numerical simulations based on a detailed soot description is attempted for a configuration describing the instantaneous and local effect of vortices on soot production. Results show that a simulation using stateof-the-art soot modeling has qualitative agreement with experimental data, but that additional modeling efforts are still needed to improve the accuracy of detailed soot descriptions. Nevertheless, it is valuable to use these stateof-the-art data to examine the effects of vortex interactions on soot yield due to the reasonable agreement between experiments and numerical data.

In agreement with previous numerical and experimental results [5, 19, 20], it can be seen that the total soot volume fraction is slightly higher in the case where the vortex is injected on the air side, even if both flames are subjected to similar vortex strength. The spatial distribution of $f_{v}$ is not homogeneous along the soot layer and differs in the two cases considered in Fig. 2, showing that soot production is strongly dependent on the local interaction with the vortex. This is also valid for the soot number density field (Fig. 2, third column). Indeed, the soot particle distribution varies in space along the soot layer and differs in the two cases as can be deduced by examining the concentration of small spherical particles and aggregates (Fig. 2, last column). 


\subsection{Temporal evolution of soot-flame-vortex interaction}

Simulations for smaller and higher vortex strengths $\left(V_{0}=1.5\right.$ and $V_{0}=$ 2.5 , respectively) were also carried out for both injection sides. The total soot mass $Q_{s}$ is obtained by integrating the soot mass over the whole computational domain. The evolution of the normalised total soot mass $Q_{s}^{*}=Q_{s} / Q_{s}^{\text {steady }}$ (where $Q_{s}^{\text {steady }}$ is the total soot mass of the steady flame) indicates that similar behaviors are observed for the six cases (Fig. 3). Classically, the stretch $k$ imposed by the vortex to the flame front can be decomposed into strain rate $a$ and curvature contributions:

$$
k=\left(\delta_{i j}-n_{i} n_{j}\right) \partial_{x_{j}} u_{i}+S_{d} \partial_{x_{i}} n_{i}=a+S_{d} \nabla \cdot \mathbf{n}
$$

where $\delta_{i j}$ is the Kronecker delta, $\mathbf{u}$ is the velocity, $S_{d}$ is the displacement speed and $\mathbf{n}=\nabla Z /|\nabla Z|$ is the normal to the flame front. Initially, the injection velocity drastically increases so that a strong strain rate is imposed to the flame by the vortex passage and the soot yield rapidly decreases. The soot volume fraction suppression is more effective for the strongest vortex in the first phase of the soot-vortex-flame interaction. Then, the injection velocity decreases to its initial state and the curvature becomes the main contributor to stretch since the flame is wrinkled by the rotating motion induced by the vortex. The soot yield increases and eventually exceeds its steady-state value. In this phase, the stronger the vortex, the higher the total soot production rate so that more soot is finally produced by the vortex than in the steady case. For higher values of $\tau(\tau>0.5)$, results are affected by the vortex interaction with walls and are less meaningful. Globally, the stronger

the vortex is, the more important its effect on soot production will be for 
both the initial consumption and the second formation phases. Moreover, for a given vortex strength, the soot yield is slightly higher in the case where the vortex is formed on the air side. These findings are in general agreement with the experimental results.

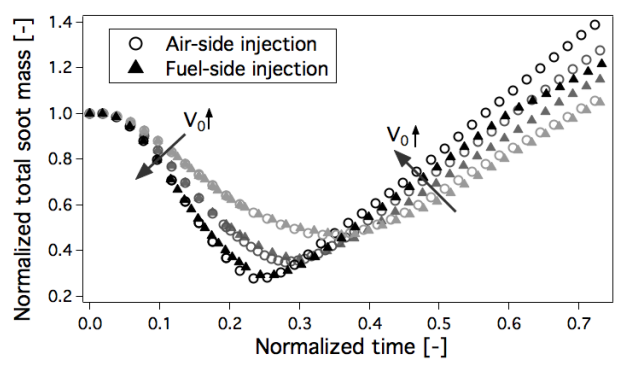

Figure 3: Time evolution of the normalized total soot mass. Air-side and fuel-side injections have been considered for the three experimental voltages $\left(V_{0}=1.5,2.0,2.5,[5]\right)$.

\subsection{Curvature effect on soot production}

As already indicated, a high strain rate is imposed to the flame during the initial soot-vortex interaction phase so that the soot volume fraction is drastically diminished. Now, it is known that the soot volume fraction of diffusion flames decreases with increasing strain rates [30, 31]. Unsteady effects of strain rate are commonly investigated by examining unsteady counterflow diffusion flames $[32,33,34]$. In contrast, the effect of flame curvature on soot production is less well documented and can be easily characterized by looking at the interaction of the formed vortex with the soot layer, i.e. for $\tau>0.2$. Soot volume fraction iso-contours colored by flame curvature are plotted in Fig. 4 for $V_{0}=2.0$ at $\tau=0.34$. An isoline of $Z_{\text {soot }}$, defined as the $Z$ value where the maximum of $f_{v}$ is located in the steady flame, is added to this graph and arrows indicate the flow direction. Isoline of $Z_{\mathrm{OH}}$, i.e. the 
$Z$-value where the maximum of $\mathrm{OH}$ radical is located in the steady flame, is also included to better locate lean $\left(Z<Z_{\mathrm{OH}}\right)$ and rich $\left(Z>Z_{\mathrm{OH}}\right)$ mixtures. High formation and oxidation regions are also identified.

The vortex passage strongly modifies the spatial distribution of soot volume fraction and number density, depending on the side of the vortex injection. The observed variations can be understood by looking at the effect of the flame curvature on soot processes and of the flow field on the soot layer.

Considering the case with air-injection (Fig. 4, top), regions $\mathrm{A}$ and $\mathrm{A}^{*}$ are characterized by a negligible flame front curvature. Due to the flow field, soot produced at this point is convected outside this region, so that the soot population is mainly characterized by nuclei and small spherical particles which have no time to growth or agglomerate. As a consequence, the num-

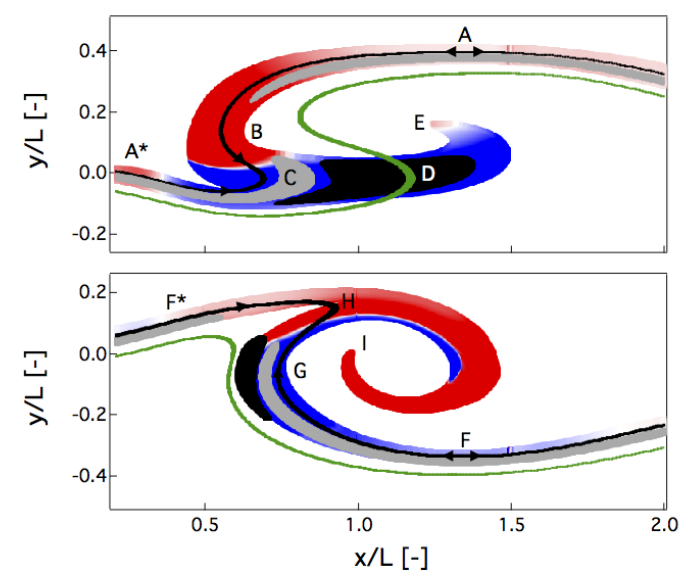

Figure 4: Soot-flame-vortex interaction for air (bottom) and fuel (top) vortex injection for case $V_{0}=2.0$ at $\tau=0.34$. Soot volume fraction iso-contours are colored by curvature (red-concave, blue-convex). The soot mass formation and oxidation regions are presented in gray and black, respectively. The iso-contour of $Z_{\text {soot }}$ is shown in black, where arrows indicate the flow direction, and of $Z_{\mathrm{OH}}$ is shown in dashed green. 
ber density and the spherical particle concentrations are highest in these zones. Point $\mathrm{B}$ presents a smaller value of the number density and of $f_{v}$. Due to the velocity field imposed by the vortex, the flame front at this point is characterized by a high concavity towards the fuel side. Soot production is almost zero and the soot volume fraction is mainly convected in this region. Aggregation is the only process occurring for the solid phase, so that the number density decreases with the collision of smaller particles into bigger aggregates. On the contrary, region $\mathrm{C}$ is characterized by a strong convexity of the flame front towards the fuel side. Due to differential diffusion effects on PAHs, the soot precursors concentration is higher in this region so that an high soot mass formation is observed. In addition, due to the flow field induced by the vortex, this zone presents a strong preferential concentration of soot which enhance the number of collisions, i.e. the agglomeration process. The preferential concentration, together with increasing soot formation rate, explains the high concentrations of both aggregates and spherical particles. The convective motion of the vortex pushes the soot layer, whose diffusivity is negligible compared to the gaseous species, to penetrate the $\mathrm{OH}$ front at region $\mathrm{D}$, where it is strongly oxidized explaining the drastically decreasing of $f_{v}$. Only large aggregates, which survives after passing through the OHfront, reaches region E. These large particles hardly diffuse so that they can be convected by the flow field motion inside the vortex.

The soot volume fraction field is markedly different when the vortex is injected on the fuel side (Fig. 4, bottom) but the soot behavior is a consequence of the same features observed for the air-side case. Once again, nucleation is the main soot formation process at points $\mathrm{F}$ and $\mathrm{F}^{*}$, characterized by a neg- 
ligible curvature. In the convex region $\mathrm{G}$, the soot volume fraction increases rapidly due to a high $\mathrm{PAH}$ concentration. Point $\mathrm{H}$ is characterized by a high concavity of the flame and the soot mass formation is negligible here as for the air-injection case. The flow field generates a strong preferential concentration of soot in this point, characterized by a decrease of the soot number density due to aggregation. Due to the flow field induced by the vortex and the low diffusivity of the solid phase, point I is characterized by the presence of soot aggregates that are convected towards the vortex center.

From the presented cases, some conclusions can be drawn. The vortex passage only slightly increases the flame surface and the region where soot formation occurs, whereas soot occupies a wider region. The interaction of the soot layer with the vortex depends on the vortex-injection side and leads to different soot topologies and inhomogenous soot layer characteristics, which can be explained by looking to the flame curvature. Two different sources of variability can be recognized. First, it exists a differential diffusion effect between gaseous and solid phases. A concave/convex curvature is the result of a convective motion towards lean/rich regions acting on both the gaseous and the solid phase. The solid phase and in particular large aggregates characterized by high Schmidt numbers are mainly governed by convection compared to the more diffusive gaseous species. As a consequence, the soot volume fraction will be found at leaner/richer mixture under the effect of the convective motion of the vortex, generating a variability of $f_{v}$ in the Z-space. The second effect is caused by a differential diffusion effects on PAHs. The flame front convexity enhances the heat transport from the flame towards the preheat region, increasing the PAHs concentration and, consequently, 
soot production. The spatial variability of the soot layer is governed by the flow field induced by the vortex and the way the flame front is deformed by it.

This qualitative analysis can be further supported by examining scatterplots of the $f_{v}$ as a function of the passive scalar $Z$ presented in Fig. 5. Here, the contributions of flat, convex and concave profiles are identified, as well as the results for the steady solution. It should be noted that both the maximum and the total $f_{v}$ are smaller than the steady values for both cases, since at $\tau=0.34$ the destructive effect of the strain rate has just become negligible compared to the curvature effect (Fig. 3). Compared to the steady case, the soot volume fraction presents a sizable variability, occupying a wide zone in the $f_{v}-Z$ manifold. Variations are not only observed in $f_{v}$ values, but also in their position in $Z$-space. Moreover, the two scatterplots notably differ, highlighting the strong effect of vortex-side injection on soot.

The reasons of this variability may be understood by examining scatterplots of the soot mass production rate plotted in Fig. 6 (top). Soot mass
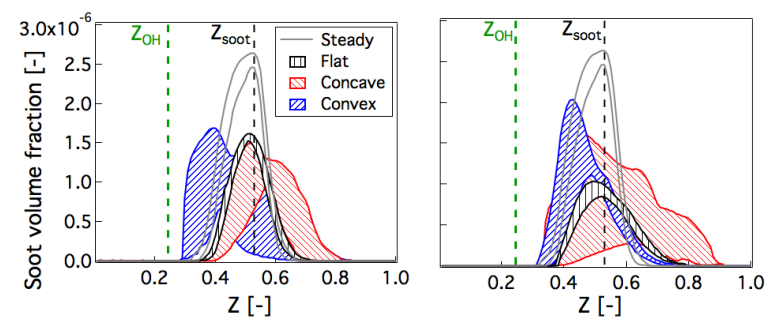

Figure 5: Scatterplot of soot volume fraction for air (left) and fuel (right) injection for case $V_{0}=2.0$ at $\tau=0.34$. Contributions for flat (black), concave (red) and convex (blue) zones are represented. Results for the steady flame are presented by grey lines. Vertical continuous and dashed lines indicate $Z_{\mathrm{OH}}$ and $Z_{\text {soot }}$, respectively. 


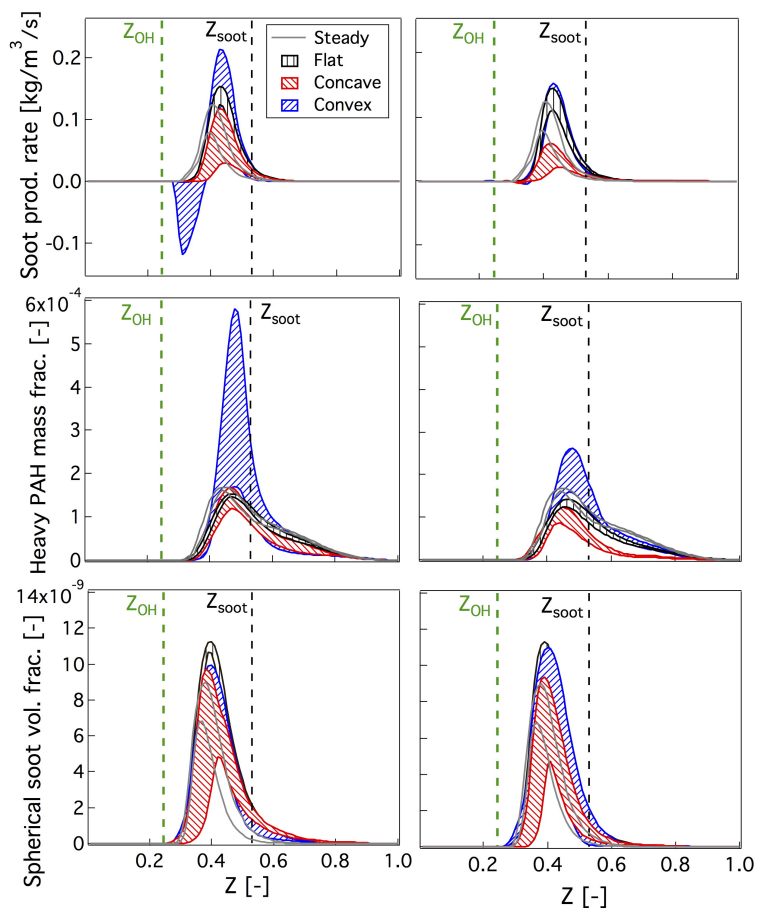

Figure 6: Scatterplot of soot mass production rate (top), heavy PAHs mass fraction (center) and spherical particles volume fraction (bottom) for air (left) and fuel (right) injection for case $V_{0}=2.0$ at $\tau=0.34$. Captions are the same as in Fig. 5.

formation rate is mainly localized at the same $Z$ observed at steady state condition, so that no greater variability in the unsteady case is observed in the $Z$-space for this quantity. Compared to the flat profile, concavity seems to have a negative effect on the formation of soot, whereas convexity increases the soot production in both injection cases. The unsteady values exceed the steady state, proving that curvature, and in particular convexity, is the source of a total soot mass production in the flame-vortex-soot configuration higher than the steady case. A strong destruction rate characterizes the airinjection case in the convex region, corresponding to the region close to zone 
D in Fig. 4, where the soot layer is pushed against the $\mathrm{OH}$ front. The positive formation rate observed for the air-injection case is higher than that obtained in the fuel-case leading to a higher total $f_{v}$ in Fig. 3 . As deduced experimentally $[5,17]$, the cause lies in the effect of flame curvature on the production of PAHs, which are necessary for nucleation and surface growth. Looking at results for heavy PAHs (Fig.6, center), one observes that convexity towards the fuel strongly enhances their production due to the concentration of heat, transported from the flame towards the preheat region. A higher $\mathrm{PAH}$ concentration is observed in the air-injection case, since the convexity radius is considerably smaller at point $\mathrm{C}$ than at point $\mathrm{G}$. This explanation, proposed in Ref. [5] to account for the higher levels of $f_{v}$ close to convex zones, is confirmed by the present calculations. Heavy PAHs seem to be less sensitive to concavity. The maximum values of light and heavy PAH mass fractions normalized by the maximum steady value are reported in Table 1 for both injection sides and the three vortex strenghts. From this analysis, it appears that there is a direct correlation between the weight of PAH and its sensitivity to curvature. The sole response of naphthalene (which is included in the light PAH class) and of the soot production rate are also added to the table. It can be concluded that whenever the heavy PAH concentration is not negligible, as in these calculations, their response to flame curvature plays a non-negligible role in the soot production process. In these cases, the reduced models should account for heavy PAHs to reproduce the flame curvature effect on soot production rate.

The marked sensitivity of PAHs to flame curvature is expected to have a direct consequence on the volume fraction of small spherical particles, whose 


\begin{tabular}{|c|c|c|c|c|c|c|}
\hline & \multicolumn{3}{|c|}{ Air-side } & \multicolumn{3}{c|}{ Fuel-side } \\
\hline$V_{0}$ & 1.5 & 2.0 & 2.5 & 1.5 & 2.0 & 2.5 \\
\hline C10H8 & 1.16 & 1.2 & 1.2 & 0.84 & 0.96 & 1.1 \\
Light PAHs & 1.37 & 1.37 & 1.37 & 1.13 & 1.24 & 1.34 \\
Heavy PAHs & 2.35 & 3.47 & 3.64 & 1.58 & 1.7 & 1.94 \\
\hline Soot prod. rate & 1.58 & 1.8 & 1.92 & 1.33 & 1.35 & 1.33 \\
\hline
\end{tabular}

Table 1: Maximum values of PAHs mass fractions and soot production rate at $\tau=0.34$ normalized by the maximum corresponding steady values.

level strongly depends on surface growth processes (Fig.6, bottom). The instantaneous soot particle volume fraction depends on the flame curvature and is higher than the steady value in both cases. However, it should be noticed that the large variability of heavy PAHs is not completely reflected by spherical soot particles. The reason is threefold. First, the production of spherical particles is governed also by the presence of small PAHs, which are less sensitive to curvature. Second, the higher positive soot formation due to high heavy PAHs concentration observed for the air-side injection is balanced by the strong negative destruction rate due to the flow field motion pushing the soot layer against the $\mathrm{OH}$ front. Third, soot formation is characterized by long chemical time scales so that the PAHs behaviour is not yet reflected on soot spherical concentrations. As a consequence, the spherical partical concentration is similar for both injection sides. For the same reason, more time is still necessary to observe an increase of the soot volume fraction.

The behavior of heavy PAHs and small soot particles is not sufficient to 
explain the variability in the $Z$-space observed for the soot volume fraction (Fig. 5). Results for the large aggregates (not shown) indicate a strong analogy with the scatterplots of $f_{v}$, since they are the main contributors to soot volume fraction. Even if flat zones locate the maximum value at $Z_{\text {soot }}$ in the steady case, the concave (convex) zone is characterized by a strong variability for $Z>Z_{\text {soot }}\left(Z<Z_{\text {soot }}\right)$ for the fuel (air)-injection case. This can be explained by looking at the soot-flame-vortex interaction in Fig. 4. Due to differential diffusion between the solid particles and the gaseous species, soot aggregates are mainly driven by convection and affected to a lesser extent by diffusion, so that in the concave (convex) regions soot particles are pushed towards richer (leaner) zones due to vortex motion. This is even more pronounced when soot penetrates the vortex in richer zones in the case of fuel-injection and leaner zone for air-injection (points $\mathrm{E}$ and I in Fig. 4, respectively). The relevance of the high Schmidt number on the soot variability has already been observed in DNS of turbulent flames in the scalar dissipation rate space [14]. Here, it is possible to identify the effect of convexity and concavity on this variability by studying a simpler soot-flamevortex interaction. This effect is not observed on small spherical particles since their diffusivity is higher than that of aggregates and also because in the penetration zones the soot volume fraction is mainly determined by aggregates.

\section{Conclusions}

To improve the understanding of soot formation and oxidation in turbulent flames, it is useful to examine soot-vortex-flame interactions. This is 
accomplished in this article by detailed numerical modeling of the interaction between a line vortex and an acetylene-air laminar diffusion flame configuration, investigated experimentally in Ref. [5]. Results of soot volume fraction are compared to the soot LII data and the general experimental trends are reproduced. The proposed numerical strategy allows to examine effects of strain rate and flame curvature on soot production. The initial negative effect of strain rate, leading to a strong reduction of soot, is quickly balanced by the globally positive effects of curvature, so that the total soot volume fraction exceeds the steady value. Concentrations of heavy PAHs are strongly affected by flame curvature (convexity towards fuel increases their concentration), causing a strong variability in the soot production rate. The effect of curvature on PAHs increases with their sizes. Moreover, the flow field induced by the vortes is responsible for the variability of $f_{v}$ in $Z$-space since large aggregates, characterized by large Schmidt numbers, penetrate deeper into the vortex and are pushed towards leaner or richer regions depending on the vortex motion.

Findings from soot-flame-vortex interaction could be relevant to soot modeling in turbulent flames, which are know to be characterized by large curvature effects and strong and intermittent strain rates. For example, the behavior of reduced models could be usefully verified in this configuration in terms of curvature and strain rate effects on heavy PAHs, soot particles and aggregates. 


\section{Acknowledgements}

This work was performed using HPC resources from GENCI-CINES (Grant 2016-020164). Dr. Franzelli acknowledges the support of the French Association of Mechanics (Association Franaise de Mcanique).

[1] M. Smooke, C. McEnally, L. Pfefferle, R. Hall, M. Colket, Combust. Flame 117 (1999) $117-139$.

[2] M. Smooke, M. Long, B. Connelly, M. Colket, R. Hall, Combust. Flame $143(2005) 613-628$.

[3] B. Connelly, M. Long, M. Smooke, R. Hall, M. Colket, Proc. Combust. Inst. 32 (2009) $777-784$.

[4] P. Desgroux, X. Mercier, K. A. Thomson, Proc. Combust. Inst. 34 (2013) $1713-1738$.

[5] B. Cetegen, S. Basu, Combust. Flame 146 (2006) 687 - 697.

[6] M. Köhler, K.-P. Geigle, T. Blacha, P. Gerlinger, W. Meier, Combust. Flame 159 (2012) 2620-2635.

[7] S.-Y. Lee, S. Turns, R. Santoro, Combust. Flame 156 (2009) 2264-2275.

[8] B. Franzelli, P. Scouflaire, S. Candel, Proc. Combust. Inst. 35 (2015) 1921-1929.

[9] C. S. Yoo, H. G. Im, Proc. Combust. Inst. 31 (2007) $701-708$.

[10] D. O. Lignell, J. H. Chen, P. J. Smith, T. Lu, C. K. Law, Combust. Flame 151 (2007) 2-28. 
[11] D. O. Lignell, J. H. Chen, P. J. Smith, Combust. Flame 155 (2008) 316 $-333$.

[12] P. Narayanan, A. Trouvé, Proc. Combust. Inst. 32 (2009) 1481 - 1489.

[13] F. Bisetti, G. Blanquart, M. E. Mueller, H. Pitsch, Combust. Flame 159 (2012) $317-335$.

[14] A. Attili, F. Bisetti, M. E. Mueller, H. Pitsch, Proc. Combust. Inst. 35 (2015) 1251-1223.

[15] A. Attili, F. Bisetti, M. E. Mueller, H. Pitsch, Combust. Flame 161 (2014) $1849-1865$.

[16] P. G. Arias, V. R. Lecoustre, S. Roy, Z. Luo, D. C. Haworth, T. Lu, A. Trouvé, H. G. Im, Combustion Theory and Modelling (2015) 1-19.

[17] C. R. Shaddix, T. C. Williams, L. G. Blevins, R. W. Schefer, Proc. Combust. Inst. 30 (2005) $1501-1508$.

[18] P. H. Renard, D. Thévenin, J. C. Rolon, S. Candel, Prog. Energy Comb. Sci. 26 (2000) 225-282.

[19] S. Gupta, H. G. Im, Spring Technical Meeting of the Central States Section of the Combustion Institute (2012).

[20] S. Mishra, R. Santhosh, S. Basu, Int. Communications in Heat and Mass Transf. 47 (2013) $32-40$.

[21] E. Ranzi, A. Frassoldati, R. Grana, A. Cuoci, T. Faravelli, A. Kelley, C. Law, Prog. Energy Comb. Sci. 38 (2012) 468-501. 
[22] C. Saggese, A. Frassoldati, A. Cuoci, T. Faravelli, E. Ranzi, Combust. Flame 160 (2013) 1168-1190.

[23] C. Saggese, N. Sanchez, A. Frassoldati, A. Cuoci, T. Faravelli, M. Alzueta, E. Ranzi, Energy and Fuels 28 (2014) 1489-1501.

[24] C. Saggese, S. Ferrario, J. Camacho, A. Cuoci, A. Frassoldati, E. Ranzi, H. Wang, T. Faravelli, Combust. Flame 162 (2015) 3356-3369.

[25] B. Zhao, K. Uchikawa, H. Wang, Proc. Combust. Inst. 31 (2007) 851860.

[26] M. Schenk, S. Lieb, H. Vieker, A. Beyer, A. G lzhuser, H. Wang, K. Kohse-Hoinghaus, Proc. Combust. Inst. 35 (2015) 1879-1886.

[27] A. Stagni, A. Frassoldati, A. Cuoci, T. Faravelli, E. Ranzi, Combust. Flame In press (2015).

[28] A. Cuoci, A. Frassoldati, T. Faravelli, E. Ranzi, Energy \& Fuels 27 (2013) 7730-7753.

[29] A. Cuoci, A. Frassoldati, T. Faravelli, E. Ranzi, Combust. Flame 160 (2013) 870-886.

[30] M. E. Decroix, W. L. Roberts, Combust. Sci. Technol. 160 (2000) 165189.

[31] J. Xiao, E. Austin, W. L. Roberts, Combust. Sci. Technol. 177 (2005) 691-713. 
[32] A. Cuoci, A. Frassoldati, T. Faravelli, E. Ranzi, Combust. Flame 156 (2009) 2010-2022.

[33] M. E. Decroix, W. L. Roberts, Combust. Sci. Technol. 146 (1999) 57-84.

[34] P. Rodrigues, B. Franzelli, R. Vicquelin, O. Gicquel, N. Darabiha, Submitted to Proc. Combust. Inst. (2015). 